\title{
The Role of Selenite on Microglial Migration
}

\author{
LISA DALLA PUPPA,${ }^{a}$ NICOLAI E. SAVASKAN, ${ }^{b}$ ANJA U. BRÄUER, ${ }^{c}$ \\ DIETRICH BEHNE, ${ }^{a}$ AND ANTONIOS KYRIAKOPOULOS ${ }^{a}$ \\ ${ }^{a}$ Hahn-Meitner-Institute, Department of Molecular Trace Element Research \\ in the Life Sciences, 14109 Berlin, Germany \\ ${ }^{b}$ Division of Cellular Biochemistry, The Netherlands Cancer Institute (NKI), \\ 1066 CX Amsterdam, The Netherlands \\ ${ }^{c}$ Institute of Cell Biology and Neurobiology, Center for Anatomy \\ Charité-University Medical School Berlin, 10115 Berlin, Germany
}

\begin{abstract}
Oxidative brain damage, such as excitotoxicity and stroke, leads to primary neuronal destruction. The primary damage is further potentiated by macrophages and microglial cells, which are attracted and invade into the zone of damage resulting in secondary neuronal death. Since the essential trace element selenium has anti-inflammatory properties, we analyzed the effects of selenium on these inflammatory cells. Here, we show that the essential trace element selenium abrogates the stress-induced migration of microglial cells. Thus, the antimigratory effects of selenium may attenuate the secondary cell death cascade by preventing microglial invasion.
\end{abstract}

KEYWORDS: microglial migration; selenium; hydrogen peroxide; adhesion molecule expression; secondary neuronal cell death

\section{INTRODUCTION}

Microglia are the macrophage of the brain. ${ }^{1}$ Activation of microglial cells occurs during the pathogenesis of various neurologic diseases. Activated microglial cells are characterized by an amoeboid morphology, which is associated with an enhanced phagocytotic activity, upregulation of various immunoeffector molecules, and the production of inflammatory and cytotoxic factors. ${ }^{2}$ Activated microglia shows an upregulation of integrins. Integrins comprise a large family of cell adhesion molecules that mediate interactions between the extracellular environment and the cytoplasm. They regulate many aspects of

Address for correspondence: Lisa Dalla Puppa, Hahn-Meitner-Institute, Department of Molecular Trace Element Research in the Life Sciences, Glienicker Str. 100, 14109 Berlin, Germany. Voice: +49-30-8062-2785; fax: +49-30-8062-2781.

e-mail: dallapuppa@web.de

Ann. N.Y. Acad. Sci. 1096: 179-183 (2007). (C) 2007 New York Academy of Sciences.

doi: 10.1196/annals.1397.084 
cell behavior, including survival, proliferation, migration, and differentiation. The integrins are transmembrane receptors that consist of noncovalently bound heterodimers composed of $\alpha$ and $\beta$ chains. ${ }^{3}$ Recent evidence indicates that the microglial migration is strongly controlled by the expression of the integrin CD11a, which is upregulated following microglial activation. Microglial activation is thought to be protective via destruction of pathogens, removal of debris, and promotion of tissue repair; however, excess activation can be deleterious.

Significant health benefits have been attributed to selenium. Selenium has been shown to be a nutritionally essential trace element to mammals, including humans. ${ }^{4}$ Selenium is needed for the proper functioning of the immune system and also plays a crucial role in the operation of the central nervous system. ${ }^{5}$ Selenium is specifically incorporated as the amino acid selenocysteine (Sec) into numerous selenoproteins which are responsible for the essential functions in the organism. ${ }^{6} \mathrm{Sec}$ is encoded by the UGA triplet, which typically functions as stop codon. ${ }^{7}$ For Sec insertion at UGA codons, a specific RNA stem loop structure is required that resides in eukaryotes in the $3^{\prime}$ - untranslated region of the mRNA (the so-called selenocysteine-insertion-sequence [SECIS]). ${ }^{8}$ Furthermore, a specific SECIS-binding protein (SBP2) and the Sec-specific elongation factor are required for the specific function of UGA as a Sec codon. All the mammalian selenoproteins identified to date are enzymes with the Sec residue responsible for their catalytical functions. Selenium exerts its functions by altering the expressions of selenoproteins.

\section{MATERIALS AND METHODS}

\section{Cell Culture}

BV2 murine microglial cell line, which exhibits morphological and functional properties comparable with primary microglial cells, were cultured in DMEM medium supplemented with 10\% fetal calf serum (Biochrom, Berlin, Germany), $50 \mathrm{U}$ penicillin, and $50 \mu \mathrm{g} / \mathrm{mL}$ streptomycin (Gibco, Eggenstein, Germany). Activation of microglia was performed by incubation with $250 \mu \mathrm{M}$ $\mathrm{H}_{2} \mathrm{O}_{2}$ (Sigma, Taufkirchen, Germany); treatment with selenium was performed by incubation with $500 \mathrm{nM}$ sodium selenite $\left(\mathrm{Na}_{2} \mathrm{SeO}_{3}\right.$; Sigma).

\section{Migration Assay and Morphological Aspects}

For the migration assay, cells were plated at $2 \times 10^{4} / \mathrm{cm}^{2}$ in 2-well chamber slide (Nunc, Wiesbaden, Germany) and treated with $500 \mathrm{nM}$ sodium selenite. After $12 \mathrm{~h}$ incubation, $250 \mu \mathrm{M} \mathrm{H}_{2} \mathrm{O}_{2}$ was added, and after the indicated time, cells were observed under light microscopy and counted. For the statistical quantification, cells were counted by five independent investigators in a blind manner. Data are expressed as mean $\pm \mathrm{SD}$. 


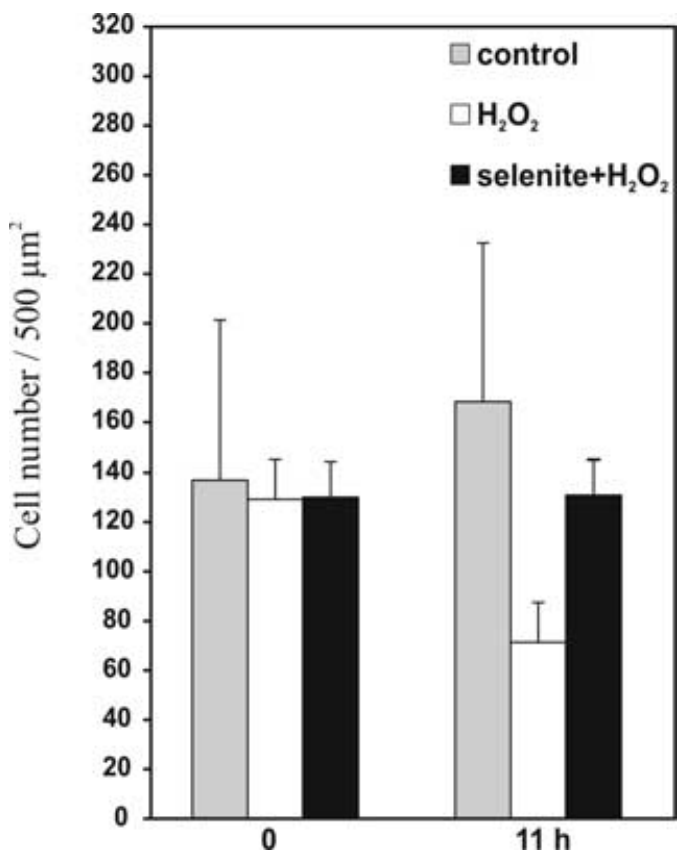

FIGURE 1. Migration assay. Control: untreated cells. $\mathrm{H}_{2} \mathrm{O}_{2}$ : cells incubated with 250 $\mu \mathrm{M} \mathrm{H}_{2} \mathrm{O}_{2}$ for the indicated time. Selenite $+\mathrm{H}_{2} \mathrm{O}_{2}$ : cells incubated with $500 \mathrm{nM}$ selenite for $12 \mathrm{~h}$ and with $250 \mu \mathrm{M} \mathrm{H}_{2} \mathrm{O}_{2}$ for the indicated time.

\section{FACS Analysis of CD11a}

The surface expression of CD11a on BV2 cells was determined using a Becton Dickinson Fluorescence Activated Cell Sorter (FACS) (Becton Dickinson, Franklin Lakes, NJ). After treatment, cells were harvested, fixed with 4\% PFA, and aliquots of $5 \times 10^{5}$ cells were resuspended with $100 \mu \mathrm{L}$ FACS buffer. The tubes were centrifuged at $300 \mathrm{~g}$ for $5 \mathrm{~min}$. The cell pellets were resuspended in $50 \mu \mathrm{L}$ FACS buffer containing PE-conjugated monoclonal rat antimouseCD11a (dilution 1:100; BD Bioscience, Heidelberg, Germany) antibody. After $10 \mathrm{~min}$ incubation at $4^{\circ} \mathrm{C}$ in the dark, $1 \mathrm{~mL}$ FACS buffer was added to each sample and centrifuged at $300 \mathrm{~g}$ for $5 \mathrm{~min}$. Obtained pellets were resuspended in $300 \mu \mathrm{L}$ of FACS buffer and finally analyzed by FACS Flow Cytometer using the FL2 range for PE-CD11a.

\section{RESULTS AND DISCUSSION}

\section{Selenium Treatment Reduced Stress-Induced Migration in BV2 Cells}

For the migration assay, BV2 cells were plated in chamber slide and treated with selenite and hydrogen peroxide as described in methods. Cells treated 


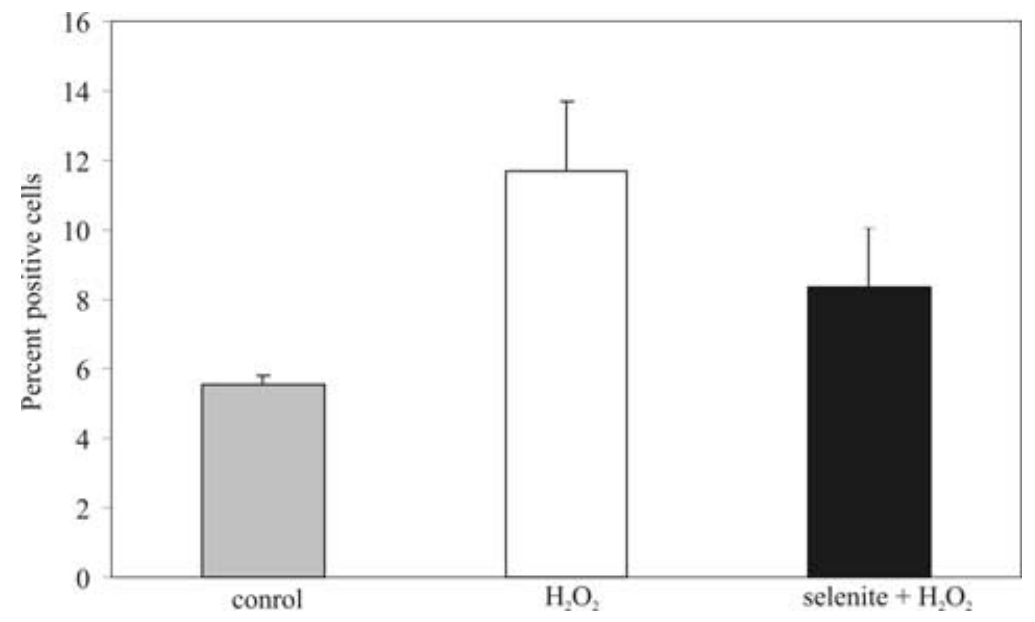

FIGURE 2. FACS analysis of CD11a expression in BV2 cells after preincubation with $500 \mathrm{nM}$ selenite $\left(\mathrm{Na}_{2} \mathrm{SeO}_{3}\right)$ and stimulation with $250 \mu \mathrm{M}$ hydrogen peroxide $\left(\mathrm{H}_{2} \mathrm{O}_{2}\right)$. Data are given as positive cells $\pm \mathrm{SD}, \mathrm{n}=2$.

with $\mathrm{H}_{2} \mathrm{O}_{2}$ showed a dramatic decrease of cell number after $11 \mathrm{~h}$; this effect was almost inhibited from pretreatment with selenite (FIG. 1). $\mathrm{H}_{2} \mathrm{O}_{2}$ transforms microglial cells from a resting ramified form into an activated amoeboid form. This morphological transformation was prevented by selenite supplementation. The inhibition of microglial migration could be reached by selenite application within the physiological range.

\section{Effect of Selenium on Adhesion Molecule Expression}

The expression of the surface integrin subunits CD11a (LFA-1 $\alpha$ chain) on BV2 cells was quantified by means of flow cytometry. Cells were either unstimulated or activated with hydrogen peroxide. As shown in FIGURE 2, expression of CD11 a was upregulated after $\mathrm{H}_{2} \mathrm{O}_{2}$ treatment, pretreatment with sodium selenite reduced BV2-induced activation. The influence of selenite in modulation of the adhesion molecule expression indicates a role of selenium in immune response of microglia.

The results of this study indicate that selenium plays an important role in the prevention of the microglial activation and therefore may reduce the impact of the secondary damage.

The protective function of selenium in primary oxidative destruction of neurons was shown to require de novo protein synthesis ${ }^{9}$; and it is very likely that the effects of this essential element on microglia are caused by upregulation of specific selenoenzymes, which abrogate microglial migration and activation. 


\section{ACKNOWLEDGMENTS}

This study was supported by a grant from the Deutsche Forschungsgemeinschaft within the DFG Priority Programme "Selenoproteins" (SPP 1087). We thank Dr. Christine Brandt (Center for Anatomy, Charité, Berlin) for the FACS analysis. N.E. Savaskan is supported by the Human Frontiers Science Program (HSFP).

\section{REFERENCES}

1. KreutzBerg, G.W. 1996. Microglia: a sensor for pathological events in the CNS. Trends Neurosci. 19: 312-318.

2. GiuLiAN, D. et al. 1989. The role of mononuclear phagocytes in wound healing after traumatic injury to adult mammalian brain. J. Neurosci. 9: 4416-4429.

3. MiLNER, R. \& I.L. CAMPBELL. 2002. The integrin family of cell adhesion molecules has multiple functions within the CNS. J Neurosci. Res. 69: 286-291.

4. BehNe, D. \& A. Kyriakopoulos. 2001. Mammalian selenium-containing proteins. Annu. Rev. Nutr. 21: 453-473.

5. SCHWEIzER, U. et al. 2004. Selenium and brain function: a poorly recognized liaison. Brain Res. Brain Res. Rev. 45: 164-178.

6. Kyriakopoulos, A. \& D. BeHNE. 2002. Selenium-containing proteins in mammals and other forms of life. Rev. Physiol. Biochem. Pharmacol. 145: 1-46.

7. HatField, D.L. \& V.N. GLAdYSHEV. 2002. How selenium has altered our understanding of the genetic code. Mol. Cell Biol. 22: 3565-3576.

8. Copeland, P.R. 2003. Regulation of gene expression by stop codon recoding: selenocysteine. Gene 312: 17-25.

9. Savaskan, N.E. et al. 2003. Selenium deficiency increases susceptibility to glutamate-induced excitotoxicity. FASEB J. 17: 112-114. 